\title{
BMJ Open What is the current NHS service provision for patients severely affected by chronic fatigue syndrome/myalgic encephalomyelitis? A national scoping exercise
}

\author{
Clare McDermott, ${ }^{1}$ Atheer Al Haddabi, ${ }^{2}$ Hiroko Akagi, ${ }^{3}$ Michelle Selby, ${ }^{4}$ Diane Cox, ${ }^{5}$ \\ George Lewith ${ }^{1}$
}

To cite: McDermott C, Al Haddabi A, Akagi $\mathrm{H}$, et al. What is the current NHS service provision for patients severely affected by chronic fatigue syndrome/myalgic encephalomyelitis? A national scoping exercise. BMJ Open 2014;4:e005083.

doi:10.1136/bmjopen-2014005083

- Prepublication history for this paper is available online. To view these files please visit the journal online (http://dx.doi.org/10.1136/ bmjopen-2014-005083)

Received 26 February 2014 Revised 21 May 2014 Accepted 22 May 2014

CrossMark

For numbered affiliations see end of article.

Correspondence to

Clare McDermott;

C.McDermott@soton.ac.uk

\section{ABSTRACT}

Background: Chronic fatigue syndrome/myalgic encephalomyelitis (CFS/ME), in its most severe clinical presentation, can result in patients becoming housebound and bedbound so unable to access most available specialist services. This presents particular clinical risks and treatment needs for which the National Institute for Health and Care Excellence (NICE) advises specialist medical care and monitoring. The extent of National Health Service (NHS) specialist provision in England for severe CFS/ME is currently unknown.

Objectives: To establish the current NHS provision for patients with severe CFS/ME in England.

Setting and participants: All 49 English NHS specialist CFS/ME adult services in England, in 2013.

Method: Cross-sectional survey by email questionnaire.

Primary outcome measures: Adherence to NICE guidelines for severe CFS/ME.

Results: All 49 services replied (100\%). 33\% (16/49) of specialist CFS/ME services provided no service for housebound patients. 55\% (27/49) services did treat patients with severe CFS/ME and their interventions followed the NICE guidelines. The remaining services $(12 \%, 6 / 49)$ offered occasional or minimal support where funding allowed. There was one NHS unit providing specialist inpatient CFS/ME provision in England.

Conclusions: Study findings highlight substantial variation in access to specialist care for patients with severe presentation of CFS/ME. Where treatment was provided, this appeared to comply with NICE recommendations for this patient group.

\section{INTRODUCTION}

Chronic fatigue syndrome, also known as myalgic encephalomyelitis (CFS/ME), is an illness characterised by debilitating physical and mental fatigue, pain and other symptoms. It is estimated to affect up to 250000

\section{Strengths and limitations of this study}

- Our survey received a $100 \%$ response from the 49 chronic fatigue syndrome/myalgic encephalomyelitis specialist services in the National Health Service (NHS) in England and all data queries were resolved via telephone or email.

- The study collected data on adult specialist CFS/ ME services only. Further research is needed to determine paediatric service provision.

- While this study collected data on service provision, it did not collect data on clinical outcomes for treated patients. This limitation should be addressed by further research.

people in the UK. ${ }^{1}$ At its most severe, CFS/ME can lead to individuals becoming housebound, wheelchair user or bedbound and dependent on carers for all basic activities of daily living. ${ }^{2}$ The illness can last for decades, leaving many severely affected individuals profoundly disabled for many years, although others return to health within a much shorter time. There has been little research to establish the prevalence or prognosis of severe $\mathrm{CFS} / \mathrm{ME}$. $^{3}$

Severe CFS/ME presents particular clinical risks, as noted by the NICE guidelines. ${ }^{1}$ Patients who are bedridden for a long period may have associated medical risks, including postural hypotension, deep venous thrombosis, osteoporosis, pressure sores and deconditioning. Symptoms including malaise and nausea, combined with impaired physical mobility for tasks of daily living have led to reported instances of patients becoming dehydrated or critically underweight, leading to emergency hospital admissions. The NICE guidelines recommend that all patients with severe CFS/ME receive specialist medical 
care to monitor clinical risks, and to advise on individually tailored treatment plans. ${ }^{1}$

While significant progress has been made in researching and treating CFS/ME in mild-to-moderately affected individuals, housebound patients are generally too ill to travel to outpatient appointments for treatment. There has been little formal research conducted on this patient group, as highlighted by successive national reports on CFS/ME. ${ }^{1}{ }^{4}$ Nevertheless, case reports, pilot studies and anecdotal evidence suggest that substantial improvement or recovery is possible for some patients given specialist intervention individualised to patient need. ${ }^{256}$ Within this context, what specialist care is currently provided by the National Health Service (NHS) in England for this patient group?

Our searches of published literature and consultation with national organisations indicated that no systematic data had been collected to date on this question. The aim of this scoping exercise was to ascertain current service provision within the NHS for severe CFS/ME within England. This study was conducted as part of a $\mathrm{PhD}$ doctoral fellowship funded by the National Institute for Health Research (NIHR) School for Primary Care Research. The team comprised independent researchers and representatives from the British Association for CFS/ME (BACME), which is the national 'umbrella organisation' representing specialist NHS CFS/ME services in the UK (http://www.bacme.info).

\section{Background to study}

In 2013, there were 49 specialist adult CFS/ME services in the NHS in England. ${ }^{7}$ While all specialist CFS/ME NHS services in the UK follow the 2007 National Institute for Health and Care Excellence (NICE) guidelines for diagnosing and treating CFS/ME, each service is autonomous in how they choose to implement this guidance in clinical practice. The 2007 NICE guidelines on CFS/ME offer 'general principles of care' for severe CFS/ME (summarised in box 1). ${ }^{1}$

\section{METHOD}

This scoping exercise was a cross-sectional study conducted by an emailed questionnaire. Questionnaire design was guided by existing research literature, discussions with specialist health professionals and consultation with two patient support groups who provided Patient and Public Involvement (PPI) for the study (The Association of Young People with ME and the Dorset ME Support Group).

In this study, we defined 'severe CFS/ME' as patients who are predominantly housebound or bedridden, in accordance with the Cox and Findley ${ }^{8}$ severity categories for CFS/ME.

\section{Data collection}

Identification of services was conducted between January and February 2013 from a list provided by the
Box 1 NICE 2007 guidelines on severe chronic fatigue syndrome/myalgic encephalomyelitis (CFS/ME) (extract, page number 305 )

General principles of care

- Management of severe CFS/ME is difficult and complex and healthcare professionals should recognise that specialist expertise is needed when planning and providing care for people with severe CFS/ME.

- Diagnosis, investigations, management and follow-up care for people with severe CFS/ME should be supervised or supported by a specialist in CFS/ME.

- When making decisions about prolonged bed rest, healthcare professionals should seek advice from a specialist experienced in the care of people with severe CFS/ME. The significant physical and psychological risks associated with prolonged bed rest should be taken into account.

- Healthcare professionals working with people with severe CFS/ ME who are in bed most (or all) of the time, should explain the associated risks (such as postural hypotension, deep venous thrombosis, osteoporosis, pressure sores and deconditioning) and monitor these.

- People with severe CFS/ME should be offered an individually tailored activity management programme as the core therapeutic strategy, which may be delivered at home, or using telephone or email if appropriate, drawing on the principles of cognitive-behavioural therapy (CBT) and graded exercise therapy (GET).

British Association for CFS/ME cross-checked against lists of specialist CFS/ME services compiled by ME support groups. Initial contact with services was made by telephone or email between February and March 2013. We asked services to return the completed questionnaire and consent form by post, email or by telephone with a researcher. All services replied giving a 100\% response rate. We sent participants who completed the questionnaire by telephone a copy of their questionnaire answers to verify and return with consent form. Figure 1 provides a flowchart of data collection.

\section{RESULTS}

All 49 specialist CFS/ME adult services in the NHS in England replied.

Twenty-seven of 49 services $(55 \%)$ regularly provided face-to-face therapy and support to severely affected CFS/ME patients. Of these, 26 provided home visits and 1 offered specialist inpatient CFS/ME treatment. Sixteen of $49(33 \%)$ were not able to offer any service to housebound patients. The most commonly reported reason for this was lack of funding.

Three of $49(6 \%)$ services provided neither home visits nor inpatient care, but did give advice/support by telephone or email to severely affected patients on a regular basis. These were defined as providing a 'regular but minimal service'.

Three of $49(6 \%)$ services reported that they very occasionally provided help to severely affected patients. 

collection.
Figure 1 Flow chart of data

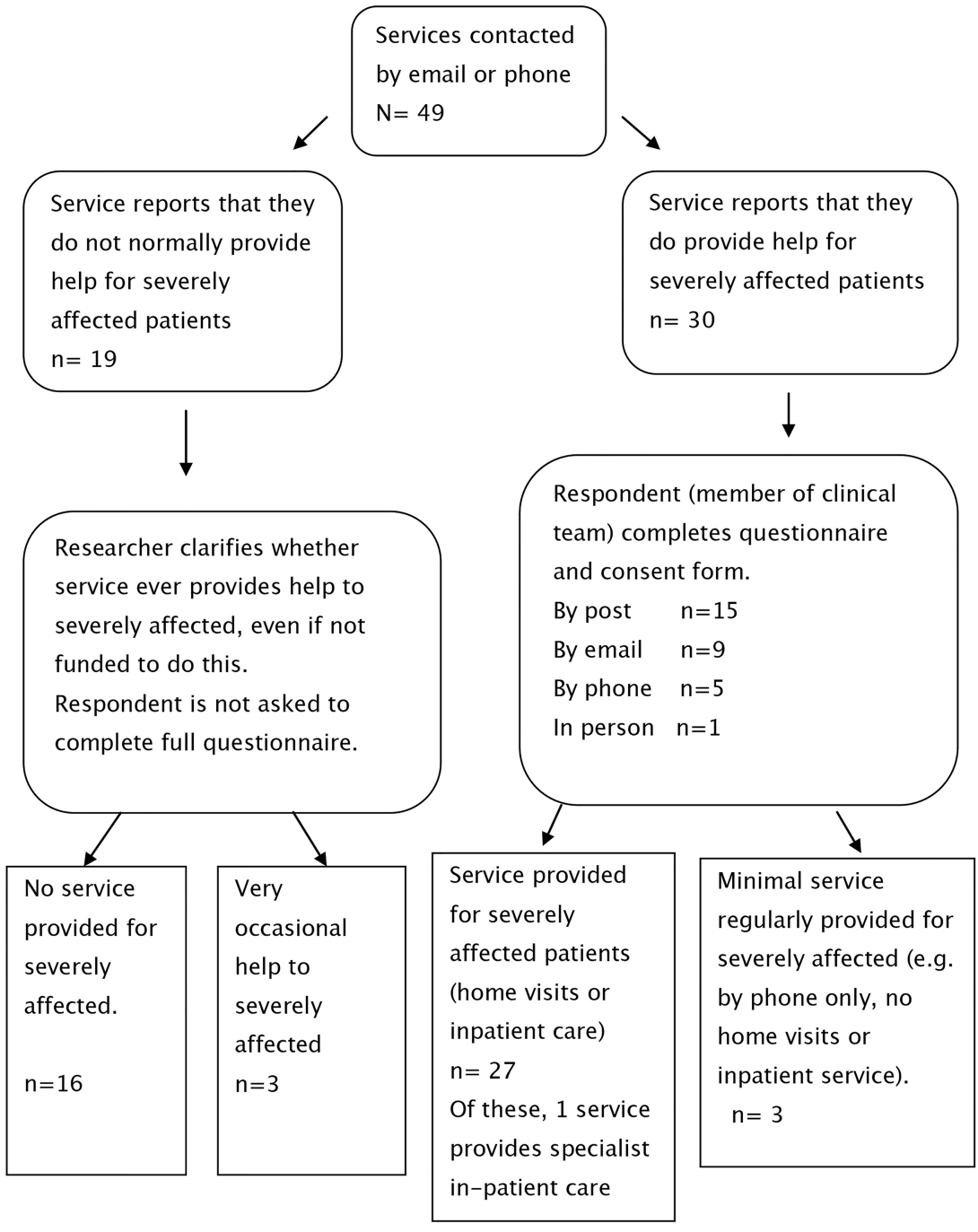

These results are summarised in figure 2.

The study identified only one NHS specialist inpatient unit in England providing treatment for patients with

Service provision for severe CFS/ME by specialist NHS CFS/ME adult services in England in 2013 $(n=49)$

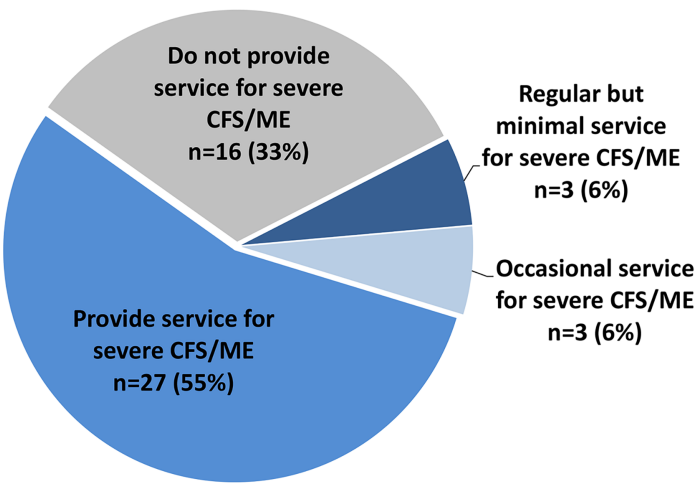

Figure 2 Provision of care for severely affected patients by specialist National Health Service chronic fatigue syndrome/ myalgic encephalomyelitis (CFS/ME) services England, 2013.
CFS/ME. This eight-bed unit accepts extracontractual (ie, 'out of area') referrals from across the UK. In addition, clinicians from four CFS/ME services reported contributing to the care of patients who had been admitted as inpatients to other hospital settings. Examples included a patient admitted to a general medical ward for comorbidities and another admitted for acute dehydration and weight loss.

Questionnaire data were analysed from the 30 CFS/ ME services which provided a regular service to severely affected patients (27 services which provided inpatient or domiciliary care, +3 services which provided 'minimal' care by telephone or email). All services completed the questionnaire. Questionnaires were returned by post $(n=15)$, email $(n=9)$, telephone $(n=5)$ or in person $(n=1)$. All missing data or data queries were resolved by phone or email. This process was completed by August 2013.

\section{Referral pathways}

All 30 services accepted general practitioner (GP) referrals. In addition, 20/30 services accepted referrals from tertiary care (ie, hospital specialists) and 12/30 services 
accepted out of area or 'extracontractual' referrals, provided that these were funded by the patient's own Clinical Commissioning Group.

\section{Diagnostic criteria}

Twenty-three of 30 (77\%) used the Centers for Disease (CDC) 1994 (Fukuda) criteria ${ }^{9}$ making this the most common case definition for diagnosis. Ten services used the CDC 1994 criteria and the recent NICE 2007 criteria. ${ }^{1}$ Five services used the NICE 2007 criteria only. Three services offered no diagnostic service and only accepted referrals from patients with prior diagnosis.

\section{Caseload}

Twenty-six of $30 \quad(87 \%)$ services provided caseload figures. Four services reported that they were unable to provide this information because their database or other data collection methods did not categorise according to illness severity.

The average (mean) caseload was 16 patients (median $\mathrm{n}=10$, range 3-90). The largest caseload was approximately 90 patients, reported by a service commissioned with the specific remit of offering treatment to patients at the severe end of the CFS/ME spectrum. All reported figures were for total caseload. Discharge policy varied between services, with some allowing patients to remain registered with the service for many years after initial intervention, and others discharging patients after much shorter periods. In general, higher caseloads tended to be reported by services which allowed patients to remain registered for longer periods. The total sum of severely affected patients on caseloads reported by all the services in England combined was 408 patients. We also asked services how many severely affected patients were on their waiting list. However, most reported that this was difficult to determine, since illness severity tended to be categorised at first appointment.

\section{Treatment approach}

All 30 services reported that they used more than one treatment approach in combination. The most commonly reported treatment approaches were activity management which was used by $28 / 30$ (93\%) services; cognitive-behavioural therapy (CBT) used by $25 / 30$ $(83 \%)$ services and graded activity used by $24 / 30(80 \%)$ services.

Participants reported tailoring treatment to individual patient need, drawing on a range of available therapies. Results are shown below in table 1 .

Many respondents provided free-text comments that highlighted variations in how different services interpreted some of these therapeutic terms. For example, while $83 \%$ of services reported that they used 'CBT', some respondents annotated this answer to comment that they incorporated some CBT-based approaches on exploring beliefs and thinking patterns, but did not have a qualified CBT therapist on the clinical team.
Table 1 Therapeutic approaches used (in combination) by CFS/ME services for severely affected patients

\begin{tabular}{lll}
\hline Therapy & $\begin{array}{l}\text { Number of } \\
\text { services using } \\
\text { this approach }\end{array}$ & $\begin{array}{l}\text { Percentage of } \\
\text { services using } \\
\text { this approach }\end{array}$ \\
\hline $\begin{array}{l}\text { Activity } \\
\text { management }\end{array}$ & 28 & 93 \\
CBT & 25 & 83 \\
Graded activity & 24 & 80 \\
$\begin{array}{l}\text { Mindfulness } \\
\text { therapy }\end{array}$ & 22 & 73 \\
$\begin{array}{l}\text { Lifestyle } \\
\text { management }\end{array}$ & 22 & 73 \\
$\begin{array}{l}\text { Dietary advice } \\
\text { Pacing (within }\end{array}$ & 21 & 70 \\
graded activity, not & 17 & 57 \\
$\begin{array}{l}\text { adaptive pacing) } \\
\text { Graded exercise }\end{array}$ & 13 & \\
$\begin{array}{l}\text { therapy } \\
\text { Counselling }\end{array}$ & 10 & 43 \\
$\begin{array}{l}\text { CBT, cognitive-behavioural therapy; CFS/ME, chronic fatigue } \\
\text { syndrome/myalgic encephalomyelitis. }\end{array}$
\end{tabular}

Similar variations in the use of terminology became apparent with the term 'pacing'. Several participants commented that they used 'pacing' in the sense of balancing rest and activity within the context of other treatments (eg, graded activity) but wished to emphasise that they did not use pacing as a 'stand-alone therapy'.

\section{Dietary assessment and advice}

Nineteen of 30 services $(63 \%)$ reported that they gave basic dietary advice, 15/30 (50\%) reported that they assessed patients for adequate nutrition and 24/30 services $(80 \%)$ could refer patients to a dietician where necessary. No service recommended exclusion diets unless the patient had been assessed and advised by an immunologist or gastroenterologist. Where services did report giving advice on diet, this was related to basic healthy eating (eg, drinking enough fluid, adequate fruit and vegetables, reducing caffeine intake).

\section{Treatment duration}

Sixteen of $30(53 \%)$ services reported that duration of treatment and follow-up was based on individual patient need, which could range between a single visit to ongoing support. Since many services reported a high level of individualisation to patient need, we did not calculate mean duration or number of sessions.

\section{Health professionals involved in delivering care}

The smallest clinical care team consisted of one doctor and one clinical psychologist. All other services (29/30, 97\%) reported multidisciplinary teams (MDTs) involving three or more different health professionals. Doctors were the most common MDT members; 27/30 (90\%) services had either a consultant or a GP with special 
interests on the team. The three services which did not have their own doctor $(3 / 30,10 \%)$, reported that they received medical input from doctors based in neighbouring teams.

Occupational therapists were the second most common MDT members. Table 2 shows results for this question.

\section{Measurement of outcomes}

Twenty of 30 services (66\%) used some or all of the CFS/ME National Outcomes Database (NOD) questionnaires. These include patient-reported outcome measures on fatigue (Chalder Fatigue Scale), ${ }^{10}$ physical function (SF-36), ${ }^{11}$ mood (Hospital Anxiety and Depression Scale; HADS), ${ }^{12}$ pain (visual analogue pain rating scale), sleepiness (Epworth Sleepiness Scale) ${ }^{13}$ and quality of life (EQ-5D). ${ }^{14}$ Other services used one or more of the NOD outcome measures listed above, plus additional outcome measures including the Work and Social Adjustment Scale. ${ }^{15}$

\section{General practitioner information}

Twenty-five of $30(83 \%)$ services reported that they had taken action to provide GPs with information about what their service provided, for example, by presentations at GP training events.

The questionnaire also included a free-text question on participants' views on barriers to service provision for severely affected patients. This data will be the subject of a separate qualitative paper.

\section{DISCUSSION}

This study found from the responses to the questionnaire emailed between February and March 2013 that

\begin{tabular}{|c|c|c|}
\hline $\begin{array}{l}\text { Health professionals } \\
\text { within multidisciplinary } \\
\text { teams }\end{array}$ & $\begin{array}{l}\text { Number of } \\
\text { services }\end{array}$ & $\begin{array}{l}\text { Percentage of } \\
\text { services }\end{array}$ \\
\hline Doctor & 27 & 90 \\
\hline Occupational therapist & 26 & 87 \\
\hline Physiotherapist & 18 & 60 \\
\hline Clinical psychologist & 15 & 50 \\
\hline Specialist nurse & 6 & 20 \\
\hline Counsellor & 3 & 10 \\
\hline Dietician & 3 & 10 \\
\hline $\begin{array}{l}\text { Clinical psychology } \\
\text { assistant or mental health } \\
\text { practitioner }\end{array}$ & 3 & 10 \\
\hline $\begin{array}{l}\text { Cognitive-behavioural } \\
\text { therapist }\end{array}$ & 3 & 10 \\
\hline $\begin{array}{l}\text { Peer specialist (individuals } \\
\text { with experience of getting } \\
\text { better from CFS/ME }\end{array}$ & 3 & 10 \\
\hline
\end{tabular}

while $55 \%$ of adult CFS/ME services in the NHS in England treated severely affected patients, 33\% did not, with the remaining services offering regular but minimal (by email or telephone) or occasional assistance to this patient group. This suggests that a substantial proportion of patients with severe $\mathrm{CFS} / \mathrm{ME}$ lack access to face-to-face, local specialist care, even when they live in an area with a CFS/ME service.

This study received replies from all 49 specialist adult CFS/ME NHS services in England as identified by BACME in February 2013. This list was checked against lists of specialist services available from national $\mathrm{ME}$ support groups to ensure that all specialist CFS/ME services had been identified and contacted. Most responders provided complete answers and the few instances of missing data were completed by further contact with the service. Therefore we have confidence that these results present an accurate picture of NHS service provision by specialist CFS/ME services in England in spring 2013.

Is there evidence that severely affected patients with CFS/ME without a local service can access specialist care from other areas? Our scoping exercise found that 12 services accepted extracontractual referrals for severe CFS/ME. However, it is important to note that since travel presents a major barrier to housebound patients, out-of-area referrals may be of limited use for this patient group unless inpatient stay is offered. This study identified only one NHS specialist inpatient unit in England providing treatment for patients with CFS/ME. This eight-bed unit accepts referrals from across the UK. The authors are also aware of several non-NHS (private or charitable) inpatient facilities which have recently accepted NHS funded referrals for severe CFS/ME, a development which highlights changes in the NHS commissioning landscape.

How does this compare with access to treatment for patients with mild-to-moderate CFS/ME? In 2012, Collin et $a l^{7}$ collected data from $46 / 49(93 \%)$ specialist CFS/ ME services and found that while $85 \%$ of (former) primary care trusts provided a specialist CFS/ME service, $8 \%$ did not $(7 \%$ services did not respond to survey). If the outcomes of the current scoping exercise are combined with those of Collin et al, it would appear that over a third of the population of patients with severe CFS/ME in England lack access to local specialist care for their condition.

How many patients in England may be affected by this lack of access to specialist care? There has been little national research on the current prevalence of severe CFS/ME. In 2004 a study was conducted in Dorset in which a postal questionnaire was sent to all patients on the clinical records for the Dorset CFS/ME Service and all members of the Dorset ME Support Group. ${ }^{16}$ Patients identified as housebound then received a formal telephone screening by an experienced CFS/ME doctor to determine whether they fulfilled CDC Control 1994 criteria for $\mathrm{CFS} / \mathrm{ME}^{9}$ and Cox and Findley ${ }^{8}$ criteria for severe/very severe CFS/ME. A key limitation was that the 
study surveyed only patients who were known either to the Dorset ME Support Group or to the Dorset CFS/ME Service. For this reason some cases may have remained unidentified. The study found 48 severely affected patients with CFS/ME within a single county (Dorset) in 2004. It is not possible to ascertain from current evidence whether case distribution is even across the UK or whether the prevalence of severe CFS/ME has remained stable over the past decade. Further research is needed to obtain systematic evidence on prevalence so that the number of patients currently affected by severe CFS/ME in the UK can be accurately determined.

The 2007 NICE guidelines on CFS/ME recommend referral of all severely affected patients for individualised therapeutic management and monitoring/management of clinical risk by health professionals with specialist expertise in CFS/ME. ${ }^{1}$ The findings of this study suggest that this recommendation is not currently being met. However, results from those services that do provide help for severe CFS/ME suggest that treatment is being offered in accordance with 2007 NICE guidelines ${ }^{1}$ including the use of MDTs and treatment individualised to patients including activity management, CBT and graded activity.

\section{CONCLUSION}

This scoping exercise highlights a lack of access to specialist care for patients who are housebound and unable to access outpatient services due to severe CFS/ME. From the findings of this study we suggest that the development of clinical services for severely affected patients requires rigorous research to determine optimal practice, so that evidence-based interventions can be funded and offered to all patients with severe CFS/ME.

\section{Author affiliations}

${ }^{1}$ Department of Primary Care and Population Science, University of Southampton, Southampton, Hampshire, UK

${ }^{2}$ Faculty of Medicine, University of Southampton, Southampton, Hampshire, UK

${ }^{3}$ Leeds and West Yorkshire CFS/ME Service, Seacroft Hospital, Leeds, Yorkshire, UK

${ }^{4}$ Dorset CFS/ME Service, Wareham Hospital, Wareham, Dorset, UK

${ }^{5}$ University of Cumbria, Lancaster, UK

Acknowledgements The authors would like to thank the Association of Young People with ME (AYME) and the Dorset ME Support Group who were Stakeholders in this research study and who reviewed the study questionnaire during study design and the draft paper prior to submission. They also thank the British Association for Chronic Fatigue Syndrome/Myalgic

Encephalomyelitis for assisting them with this study.

Contributors CM is the guarantor. CM had the original idea for this study, and drafted the study proposal as part of a PhD studentship supervised by GL. Protocol development was completed by $\mathrm{CM}$ and AAH with expert contributions from DC, HA and MS. The questionnaire was drafted by $C M$ and $\mathrm{AAH}$. It was reviewed by all authors, as well as by Patient and Public (PPI) representatives from Association of Young People with ME (AYME) and Dorset ME Support group. The final questionnaire included contributions from all authors and PPI representatives. Data was collected by AAH and CM. Data analysis was conducted by $\mathrm{CM}$ and $\mathrm{AAH}$ supervised by Dr Beth Stuart (Medical Statistician, University of Southampton). All authors contributed to the write-up.
Funding This study was conducted as part of a $\mathrm{PhD}$ doctoral fellowship funded by the National Institute for Health Research School for Primary Care Research (NIHR SPCR). The NIHR SPCR is hosted at the University of Oxford and is a partnership between the universities of Birmingham, Bristol, Keele, Manchester, Nottingham, Oxford, Southampton and University College London.

\section{Competing interests None.}

Ethics approval The study was categorised as a service evaluation, not requiring NHS ethical review. The Research Ethics Committee of the University of Southampton, Faculty of Medicine, reviewed the study and gave university ethical approval (ref 4709). We notified the Research and Development department of each of the 49 NHS Trusts which had a chronic fatigue syndrome/myalgic encephalomyelitis service participating in the study. We provided study documentation to each R\&D department and completed additional procedures (eg, audit registration) as requested by each trust.

Provenance and peer review Not commissioned; externally peer reviewed.

Data sharing statement No additional data are available.

Open Access This is an Open Access article distributed in accordance with the Creative Commons Attribution Non Commercial (CC BY-NC 3.0) license, which permits others to distribute, remix, adapt, build upon this work noncommercially, and license their derivative works on different terms, provided the original work is properly cited and the use is non-commercial. See: http:// creativecommons.org/licenses/by-nc/3.0/

\section{REFERENCES}

1. National Institute for Heath and Care Excellence (NICE). Chronic fatigue syndrome/myalgic encephalomyelitis (or encephalopathy): diagnosis and management of CFS/ME in adults and children. NICE clinical guideline 53. London: National Collaborating Centre for Primary Care, 2007

2. Burley L, Cox DL, Findley LJ. Severe chronic fatigue syndrome (CFS/ME): recovery is possible. Br J Occup Ther 2007;70:339-44.

3. Pheby D, Saffron L. Risk factors for severe ME/CFS. Biol Med 2009;1:50-74

4. Department of Health. A Report of the CFS/ME working Group: report to the chief Medical Officer of an Independent Working Group. London: Department of Health; 2002.

5. Essame C, Phclan S, Aggett P, et al. Pilot study of a multidisciplinary inpatient rehabilitation of severely incapacitated patients with the chronic fatigue syndrome. J Chron Fatigue Syndr 1998;4:51-60.

6. Burgess $\mathrm{M}, \mathrm{Chalder} \mathrm{T}$. Adolescents with severe chronic fatigue syndrome can make a full recovery. BMJ Case Rep 2011;2011:pii: bcr0120113716.

7. Collin SM, Sterne JAC, Hollingworth W, et al. Equity of access to specialist chronic fatigue syndrome (CFS/ME) services in England (2008-2010): a national survey and cross-sectional study. BMJ Open 2012;2:pii: e001417.

8. Cox D, Findley LJ. The management of chronic fatigue syndrome in an inpatient setting: presentation of an approach and perceived outcome. Br J Occup Ther 1998;61:405-9.

9. Fukuda K, Straus SE, Hickie I, et al. The chronic fatigue syndrome: a comprehensive approach to its definition and study. International Chronic Fatigue Syndrome Study Group. Ann Intern Med 1994;121:953-9.

10. Chalder T, Berelowitz G, Pawlikowska T, et al. Development of a fatigue scale. J Psychosom Res 1993;37:147-53.

11. Ware JE, Sherbourne CD. The MOS 36-item short-form health survey (SF-36). I. Conceptual framework and item selection. Med Care 1992;30:473-83.

12. Snaith RP. The Hospital Anxiety and Depression Scale. Health Qual Life Outcomes 2003;1:29.

13. Johns MW. A new method for measuring daytime sleepiness: the Epworth sleepiness scale. Sleep 1991;14:540-5.

14. The EuroQol Group. EuroQol-a new facility for the measurement of health-related quality of life. Health Policy 1990;16:199-208.

15. Mundt J, Marks I, Shear M, et al. The Work and Social Adjustment Scale: a simple measure of impairment in functioning. $\mathrm{Br} J$ Psychiatry 2002;180:461-4.

16. McDermott M. Severely affected by CFS/ME; the Dorset CFS/ME Project. Conference proceedings of the British Association of CFS/ ME; 2006. 